\title{
Stress Analysis of Buried Pipeline Installed by Horizontal Directional Drilling Using ANSYS Finite Element Software
}

\author{
Francis Temilola Olumoko1, Chinwuba Victor Ossia ${ }^{2 *}$ \\ ${ }^{1}$ Offshore Technology Institute, University of Port Harcourt, Port Harcourt, Nigeria \\ ${ }^{2}$ Applied Mechanics Research Group (AMRG), Mechanical Engineering Department, University of Port Harcourt, Port Harcourt, Nigeria \\ Email: *chinwuba.ossia@uniport.edu.ng
}

How to cite this paper: Olumoko, F.T. and Ossia, C.V. (2019) Stress Analysis of Buried Pipeline Installed by Horizontal Directional Drilling Using ANSYS Finite Element Software. World Journal of Engineering and Technology, 7, 365-378.

https://doi.org/10.4236/wjet.2019.73027

Received: May 3, 2019

Accepted: August 3, 2019

Published: August 6, 2019

Copyright $\odot 2019$ by author(s) and Scientific Research Publishing Inc. This work is licensed under the Creative Commons Attribution International License (CC BY 4.0).

http://creativecommons.org/licenses/by/4.0/

\section{c) (i) Open Access}

\begin{abstract}
In designing a horizontal directional drilling (HDD) pipeline project, designers face the challenge of determining the regions of maximum and minimum stresses on pipelines, ensuring the stability of the bore-hole from collapse and minimizing the stresses induced on the pipeline due to the bore-profile. This study analyses the stress induced on an HDD pipeline system using the ANSYS Version 18, mechanical APDL finite element (FE) software. The pipeline used as the case study was a gas transmission pipeline installed in south-west Nigeria. A macro-file for ANSYS Version 18, mechanical APDL used to model the pipeline was developed. The results showed that the maximum and minimum stresses induced on the HDD pipeline were at the top and bottom of the pipe, respectively; while the stresses on the sides were uniform $\left(\approx 888 \mathrm{~kg} / \mathrm{cm}^{2}\right)$ all through the pipeline, irrespective of element number. The maximum stress occurred at the curvature point with the highest entry angle $\left(10^{\circ}\right)$, resulting in a maximum deflection at this point. The model stress validation performed by comparing results with theoretical solutions, both with respect to radius of curvature and internal pressure, showed percentage difference (errors) less than $10 \%$. The cross sectional area validation showed a percentage difference of $0.059 \%$.
\end{abstract}

\section{Keywords}

Horizontal Directional Drilling (HDD), Finite Element Analysis (FEM), Finite Element Analysis (FEA), ANSYS Mechanical APDL

\section{Background}

\subsection{Stresses on Buried Pipeline}

The loads acting on the pipe include its weight, the internal operating pressure 
and the external pressure due to the overhead soil load [1]. Underground loads on a buried pipeline induced by the soil pressure can be divided into two parts. Firstly, there is the soil pressure which increases with the depth of cover. Then, there is the additional force caused by ground loads which decreases with increase in depth of cover [2]. The depth of embedment of pipe, type of backfill, the pipe thickness and surcharge loads are the prime factors that affect the behavior of buried pipes [3].

HDD pipelines are subjected to a combination of tension, bending, and external pressure. Drilled path design and pipe specification may be governed by these installation loads, as they could be more severe than operational loads [4]. The borehole profile and pipe properties must be considered in selecting the suitable pipe materials for an HDD installation. These two factors should be considered together to ensure that the pipeline can be installed and operated without risk of damage [5].

\subsection{Finite Element Method (FEM) for Pipeline Stress Analysis}

In the analysis and design of underground structures, the finite element method (FEM) has been used extensively as an effective numerical technique. The results more reasonably reflect the actual situation, providing an improved design procedure to avoid pipe wear and breakage [1].

Its application ranges from the study of aircraft or automobile structural framework, complicated thermal system (nuclear power plant), to the analysis of a fluid flowing through a duct, over a weir, or through the earth [6] [7] [8] developed a 3D FE program using MATLAB to examine the performance of buried pipeline subjected to large ground motion; crossing active fault.

Spectrum technique with $1 \mathrm{D}$ beam units was used by $\mathrm{Wu}$ et al. [9] to undertake dynamic earthquake analysis on oil pipelines using CAESAR II stress analysis software. Hence, critical sections and maximum stress region were identified visibly. It was concluded that reducing the bend angle could minimize the stress and displacement of underground pipelines during an earthquake. However, this study was not extended to stress analysis of deeply buried HDD pipelines. Also, Huang, et al. [10] utilized CAESAR II software to investigate the stress on underground oil pipelines in steep and high slope regions. Comparing the different simulation results showed that the movement and stress of underground oil pipelines in steep and high slope regions were drastically reduced with enhanced safety by proposing an improved laying process.

Gabar and Bilgin [11] used ABAQUS FE software package to model buried pipeline behavior under surface-induced actions, and described the pipe-soil interactions and pipe deformation. They concluded that vertical pipe deformation increased with increasing loads for various soil layers, which may cause buckling.

Xiao, et al. [1] performed analysis of glass reinforced plastics (GRP) pipeline using ANSYS and the results were generally consistent with that of the traditional CECS190 standard, based on the maximum long term vertical deformation. It 
was further concluded that FEM may be utilized for more complex underground pipes structures.

Nirmala and Rajkumar [3] also used ANSYS as FEA tool on buried UPVC pipe and suggested that the depth of backfill increases the deflection of buried pipes, and that the behaviour of buried pipes varied due to the type of backfill material. Hence, it can be observed that ANSYS has not been used as an FEA tool for HDD pipeline stress analysis.

\section{Materials and Methods}

The model was created using ANSYS, Version 18, Mechanical APDL following the flow diagram in Figure 1. The co-ordinates for the key points, exit angle, entry angle, element type and the geometric properties (such as, pipe outer diameter, thickness, length of crossing etc.); and the material properties of the steel pipe (such as, the specified minimum yield stress, poisson ratio and young modulus) were all inputted into the model at the pre-processing stage.

At the solution stage, the loads and boundary conditions such as the degree of freedom and model solution setting were clearly specified. The final stage of the model, post-processing stage, was where the deflection plots and the stress contour diagrams of the pipeline system were plotted.

\subsection{Design Input Parameters}

The pipeline used to create the model on ANSYS, Version 18, Mechanical APDL, was a gas pipeline installed by Horizontal Directional Drilling (HDD) in

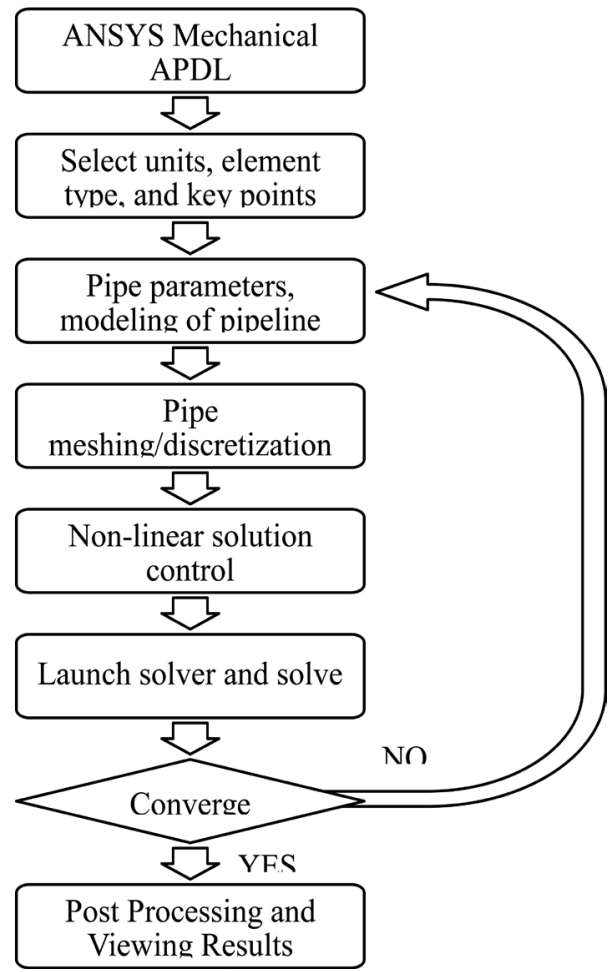

Figure 1. ANSYS Mechanical APDL design procedure flowchart. 
south-west Nigeria. The gas pipeline design parameters are shown in Table 1.

These parameters were input into the ANSYS platform to give the section outline in Figure 2. The ANSYS, Version 18, Mechanical APDL solver was used to model the pipeline. A macro file for non-linear analysis was prepared for modeling the pipeline system.

\subsection{Modeling and Meshing}

Four (4) co-ordinates points were identified on the pipeline design profile to

Table 1. Design parameters for the gas pipeline.

\begin{tabular}{cc}
\hline Parameter & Value [units] \\
\hline Pipe Diameter, OD & $91.44[\mathrm{~cm}]$ \\
Wall Thickness, $t$ & $2.06[\mathrm{~cm}]$ \\
Pipe Grade & 70 Grade \\
Specified Min. Yield Strength, SMYS & $4942.57929\left[\mathrm{~kg} / \mathrm{cm}^{2}\right]$ \\
Entry Angle & $10[\mathrm{deg}]$ \\
Exit Angle & $6[\mathrm{deg}]$ \\
Length of Crossing, $L$ & $175584[\mathrm{~cm}]$ \\
Poisson's Ratio, $\mu$ & 0.3 \\
Radius of Curvature, $R$ & $100,000\left[\mathrm{~cm}^{2}\right]$ \\
Young Modulus, $E$ & $20,400,000\left[\mathrm{~kg} / \mathrm{cm}^{2}\right]$ \\
Radius from Neutral Axis, $y$ & $45.72[\mathrm{~cm}]$ \\
Pressure at Final Hydro-Test, $P$ & $127.5\left[\mathrm{~kg} / \mathrm{cm}^{2}\right]$ \\
\hline
\end{tabular}

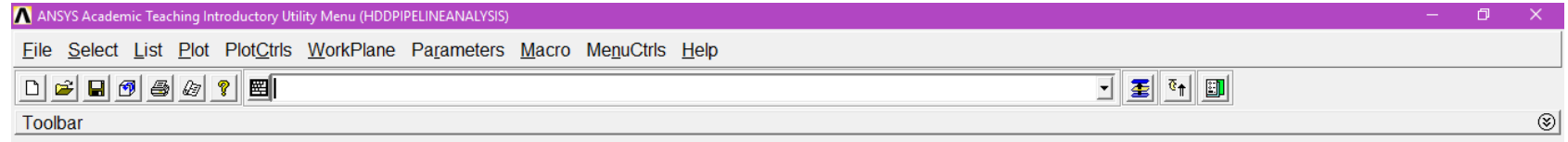

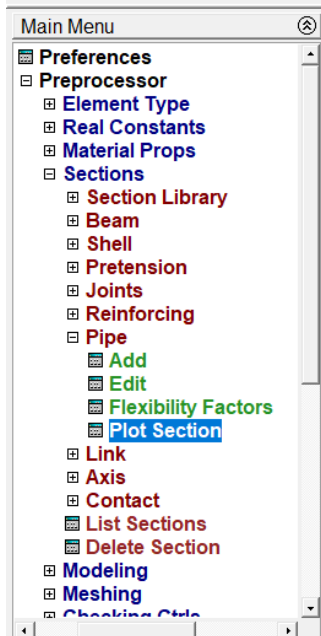
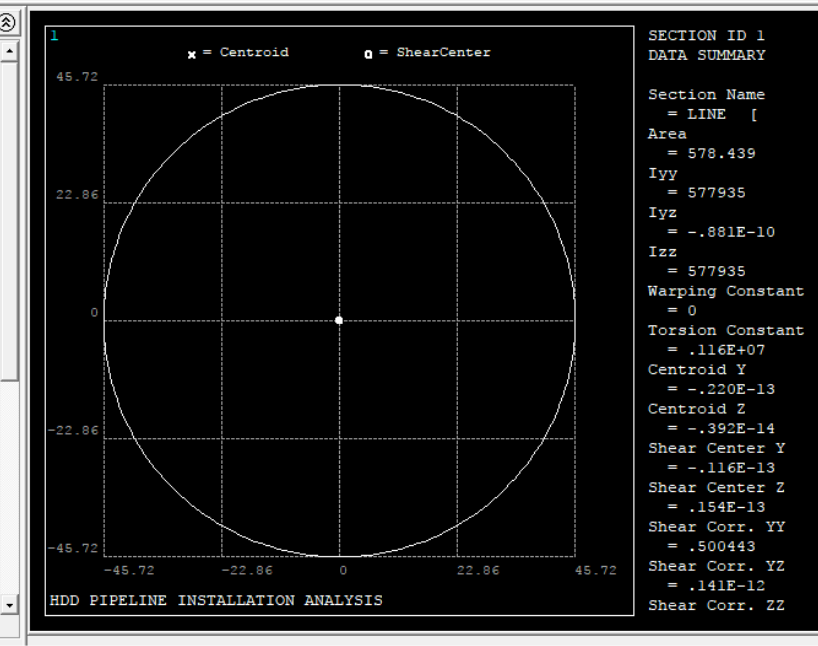

Pick a menu item or enter a command (PREP7)

mat=1

type=1

real=1

csys $=0 \quad$ secn $=1$

Figure 2. Section outline. 
serve as the key-points. The pipeline was assumed to move along the $\mathrm{x}-\mathrm{y}$ direction and therefore no co-ordinate was given for the z-direction. The radius of curvature for the sag-bends was modeled as fillet between lines 1, 2 and lines 2, 3 respectively. For this model, the radius of curvature for both sag-bends was expected to be same, with reference to the design profile. However, the exit and entry angles were different.

The number of pipe section mesh was defined for the model. The "SECNUM" command was used to identify the particular section for meshing. This command reads the section division as the amount of mesh sizes. Figure 3 shows the pipe section divisions used for the pipe meshing.

The "LMESH" command was used to generate nodes and line elements along lines. For this model, meshing was done on all the lines by selecting "ALL".

\subsection{Solutions}

\subsubsection{Loads and Boundary Conditions}

The "ANTYPE" command was used to specify the type of analysis and the restart status. For this model, the static analysis was required. The "DK" command was utilized to state the degree of freedom at the key points. For this model, at all the key points, only one degree of freedom was permitted which was in the $\mathrm{x}$-direction. The $\mathrm{y}$ - and $\mathrm{z}$-directions were constrained. The "FK" command was used to define the applied load in the $\mathrm{x}$-direction at the key points. This applied load is the force of the rig which pulls the pipe in the x-direction. The "ALLSEL" command was used to select all entities.

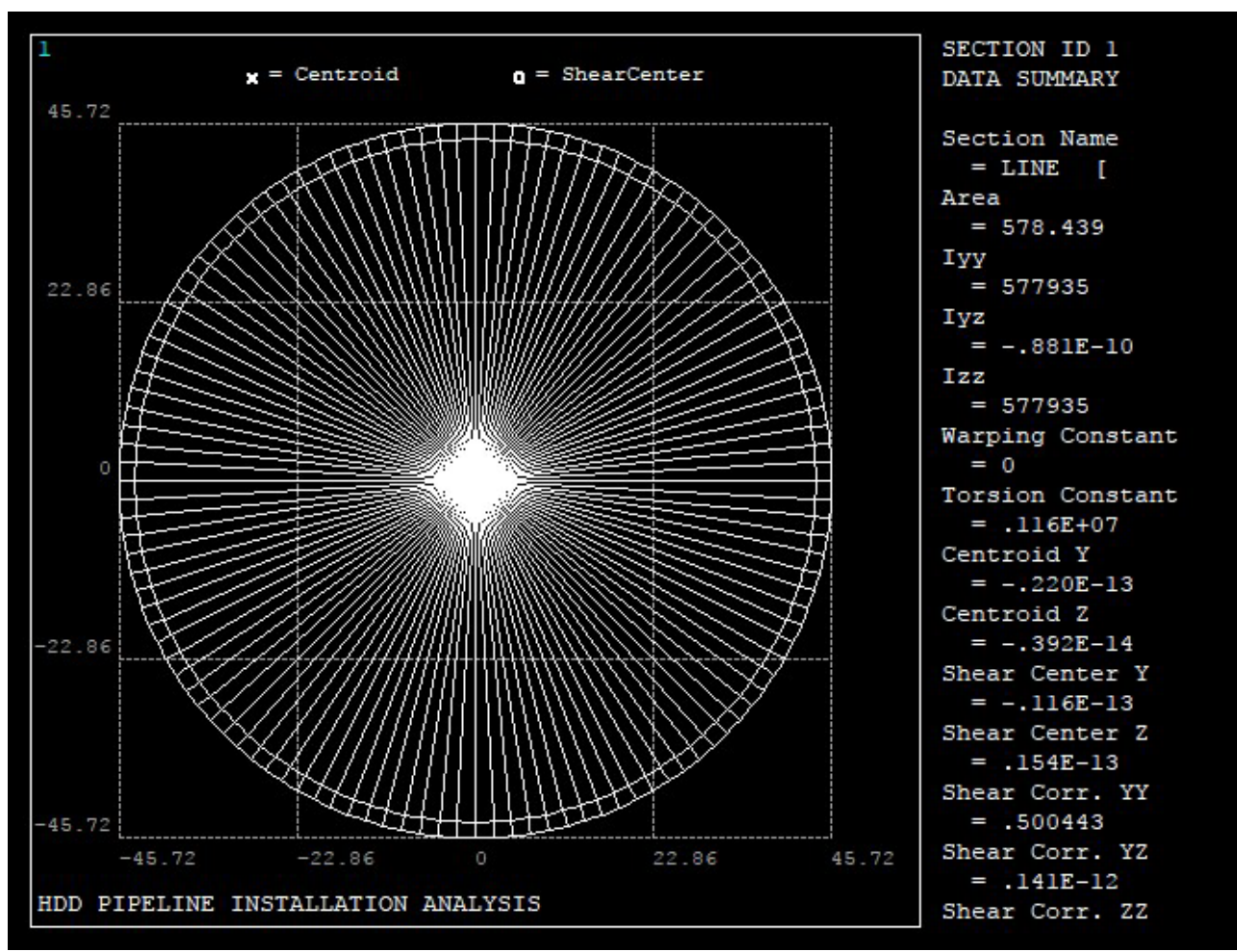

Figure 3. Pipe size meshing. 


\subsubsection{Non-Linear Solution}

The "NLGEOM" command was used to set out the large displacement static analysis option for the model. The time control for maximum (100), minimum (10) and model's number (100) of sub-steps for the basic solution control were also set.

Under the solution options, the "program chosen solver" and number $(\mathrm{N})$ of subsets-1000 were selected for the equation solvers. Under the non-linear solution options of the solution controls, the highest number of iterations (1000), line search and DOF solution predictor was logged in and selected. The solution was generated using the macro file. A screen shot of the non-linear solution while converging can be viewed on Figure 4.

\subsection{Theoretical Equivalent Resultant Stress}

The equivalent resultant stress or Von Mises stress, expressed as a combination of all the stresses acting on the walls of the pipe includes: bending, longitudinal, hoop and radial stresses. However, the radial stress for thin wall material can be taken as negligible. Hence, the equivalent resultant stress can be expressed as Equation (1).

$$
S_{\text {theory }}=\sqrt[2]{\left(\sigma_{l}^{2}-\left(\sigma_{l} * \sigma_{h}\right)+\sigma_{h}^{2}\right.}
$$

where bending stress, hoop stress and longitudinal stress are defined by equations (2), (3) and (4), respectively.

1) Bending stress,

$$
\sigma_{b}=E * \frac{y}{R}
$$

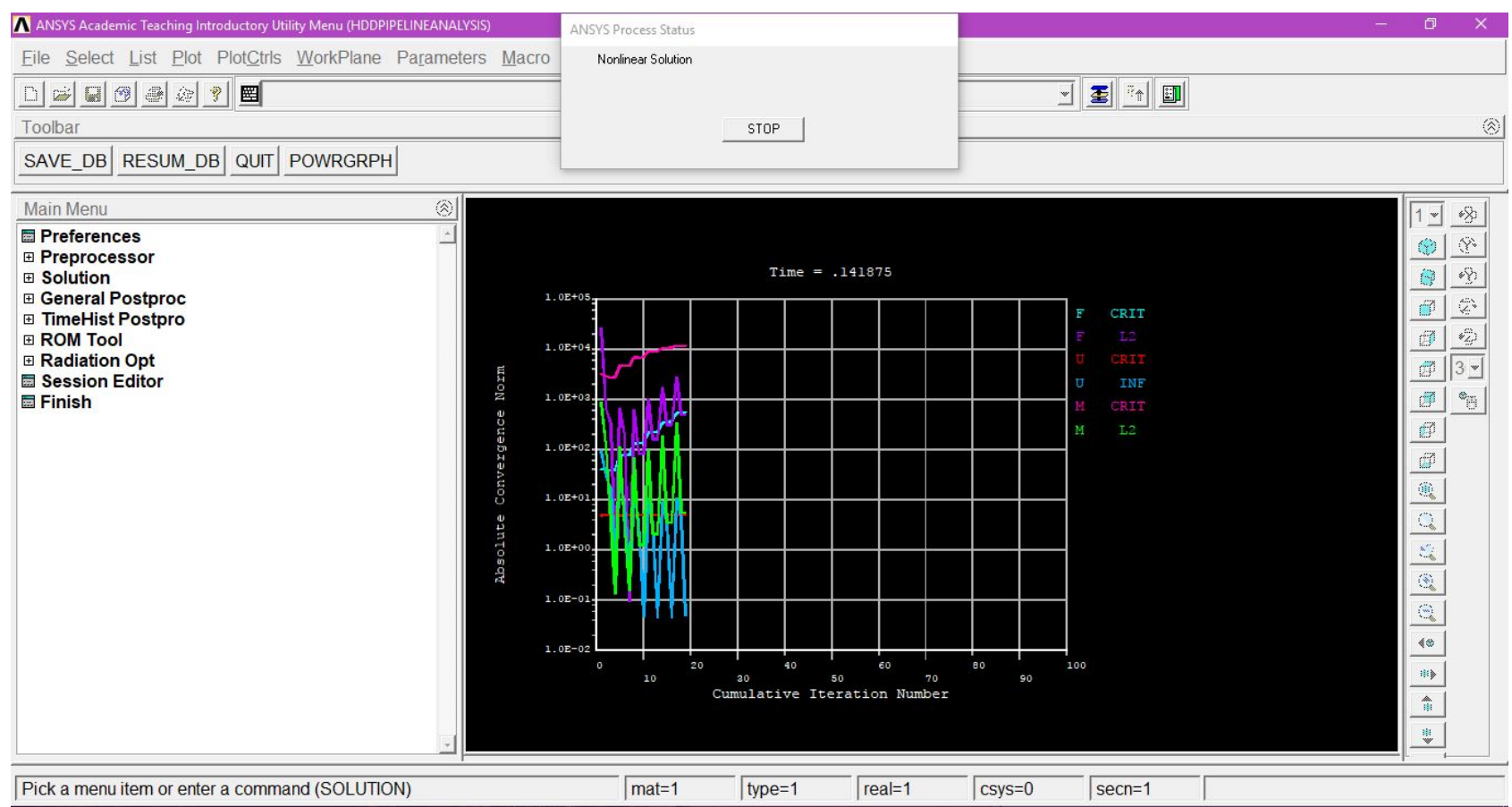

Figure 4. Non-linear solution of the macro file in-progress. 
2) Hoop stress,

$$
\sigma_{h}=\frac{P^{*} O D}{2 * t}
$$

3) Longitudinal stress,

$$
\sigma_{l}=\left(\mu * \sigma_{h}\right)+\sigma_{b}
$$

After running the ANSYS model using the relevant input parameters, the maximum equivalent stress obtained was $S_{\text {ANSYS }}$. The percentage error when comparing the resultant equivalent stress values from both theoretical calculation and ANSYS model was evaluated using Equation (5).

$$
\text { Percentage Difference }=\left(\frac{\mathrm{S}_{\text {ANSYS }}-\mathrm{S}_{\text {theory }}}{\mathrm{S}_{\text {ANSYS }}+\mathrm{S}_{\text {theory }}}\right) * 100 \%
$$

For the ANSYS model validation and investigate the effect of the HDD radius of curvature on the pipeline stresses, the internal pressure was kept constant at $P$ $=127.5 \mathrm{~kg} / \mathrm{cm}^{2}$ and different $R$-values $(90,000 \mathrm{~cm} \leq R \leq 120,000 \mathrm{~cm})$ were applied to obtain different $S_{\text {theory }}, S_{\text {ANSYS }}$ and percentage (\%) difference which results were shown in Figure 5. Similarly, to investigate the effect of internal pressure on the HDD pipeline stresses, the pipe radius of curvature was kept constant at $R=100,000 \mathrm{~cm}$ while the internal pressure applied was varied in the range 90 $\mathrm{kg} / \mathrm{cm}^{2} \leq P \leq 127.5 \mathrm{~kg} / \mathrm{cm}^{2}$ to obtain different $\mathrm{S}_{\text {theory }}, \mathrm{S}_{\text {ANsys }}$ and percentage (\%) difference and the results shown in Figure 6.

\section{Results and Discussion}

\subsection{Stress Validation-Effect of Radius of Curvature}

Figure 5 showed the radius of curvature and the corresponding maximum equivalent stress obtained from theoretical method and ANSYS, respectively. From the Figure 5 it can be observed that the percentage difference between the theoretically calculated maximum resultant stress and the maximum stress obtained from the ANSYS model was less than $10 \%$ with a maximum difference of $3.49 \%$ at a radius of curvature of $90,000 \mathrm{~cm}(900 \mathrm{~m})$ and a minimum $\%$ difference of $0.22 \%$ at a radius of curvature of $110,000 \mathrm{~cm}(1100 \mathrm{~m})$. Furthermore, the percentage error followed a parabolic distribution with respect to the radius of curvature, with a minima at $R=110,000 \mathrm{~cm}$ as shown in Figure 5 .

\subsection{Stress Validation-Effect of Internal Fluid Pressure}

Figure 6 showed the variation of Von-Mises (maximum equivalent stress) with respect to internal fluid pressure of the pipeline. The results in Figure 6 showed a comparison between the theoretically calculated and ANSYS equivalent resultant stress. From Figure 6, it can be observed that the percentage difference between the theory and ANSYS results was less than $10 \%$ with a maximum difference of $9.81 \%$ at an internal pressure of $90 \mathrm{~kg} / \mathrm{cm}^{2}$ and a minimum difference of $1.44 \%$ at an internal pressure of $127.5 \mathrm{~kg} / \mathrm{cm}^{2}$. 


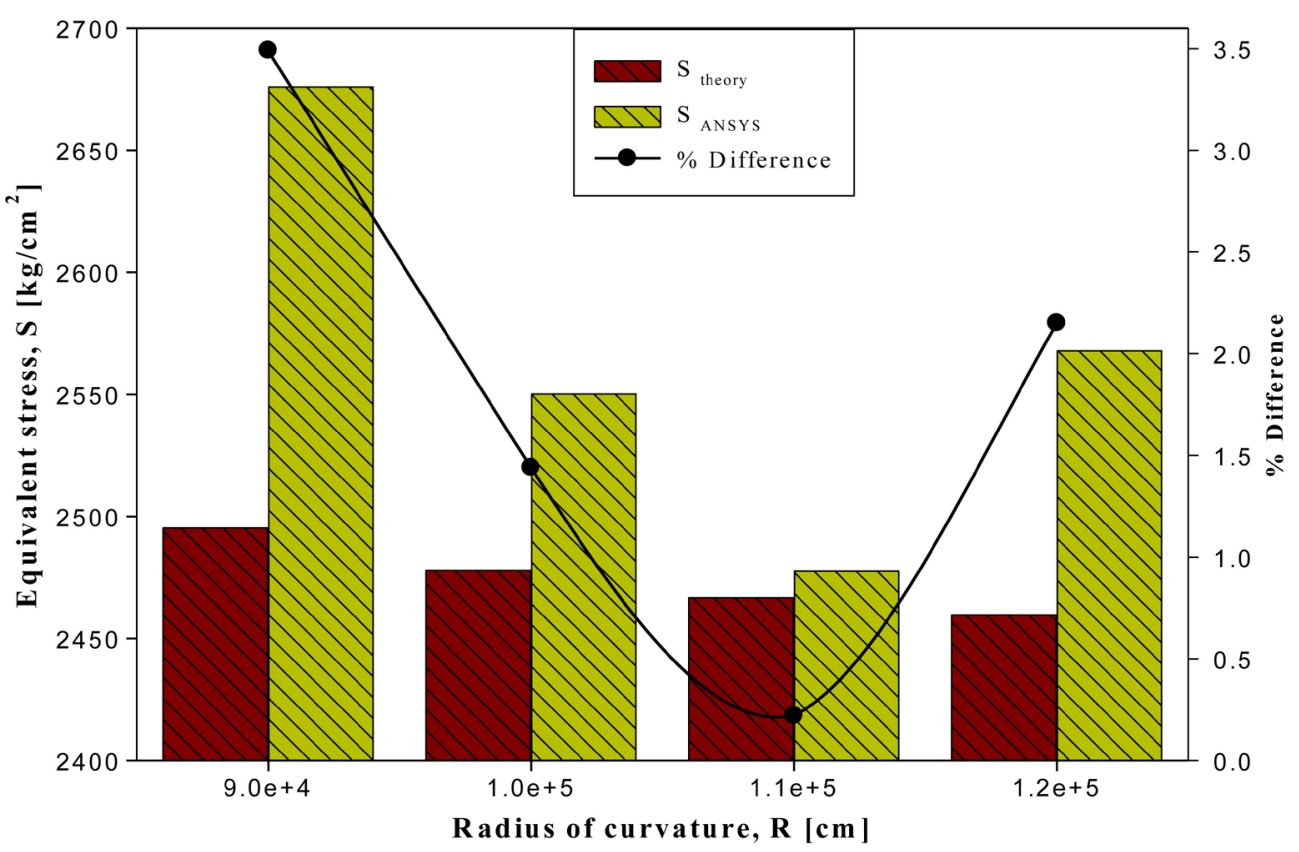

Figure 5. Effect of radius of curvature on equivalent resultant stress at $P=127.5 \mathrm{~kg} / \mathrm{cm}^{2}$.

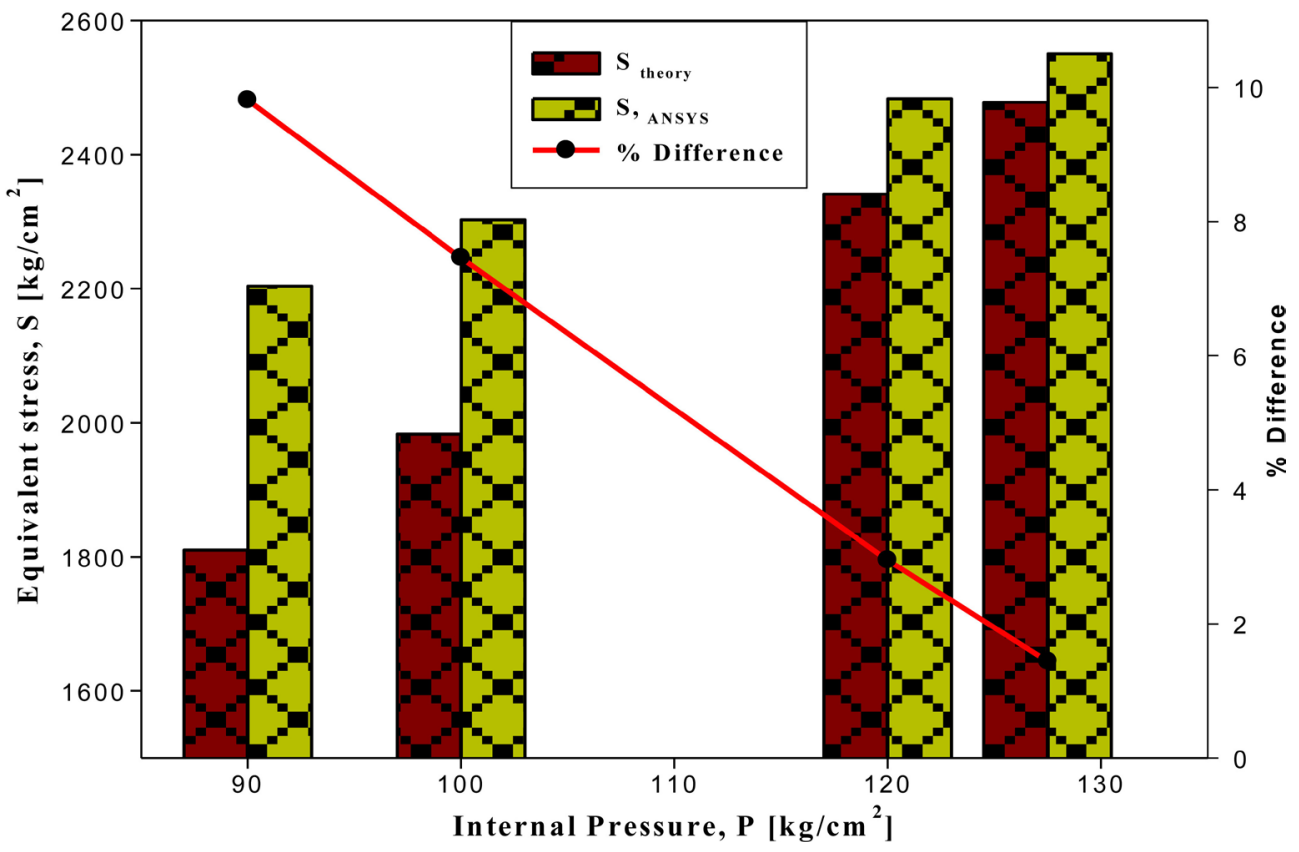

Figure 6. Effect of internal fluid pressure on equivalent resultant stress at $R=100,000 \mathrm{~cm}$.

\subsection{Cross Sectional Area Validation}

A comparison was also done between the theoretically calculated cross-section area of steel pipe and the ANSYS model cross-sectional area. The theoretically calculated cross-sectional area of the pipe is given as Equation (6).

$$
A_{s}=A_{e}-A_{i}
$$

where $A_{e}$ and $A_{i}$ are the external and internal cross-sectional area of the pipe, respectively; and $A_{s}$ was calculated as $A_{s}=579.12 \mathrm{~cm}^{2}$. 
From Figure 3, the cross-sectional area of the ANSYS model cross sectional area was obtained as $578.439 \mathrm{~cm}^{2}$. Therefore, the percentage difference in the cross-sectional area was obtained as:

$$
\text { Percentage Difference }=\left(\frac{579.12-578.439}{579.12+578.439}\right) * 100 \%=0.059 \%
$$

\subsection{Element Numbering}

The pipeline was discretized into 24 elements with 3 node points each by the ANSYS program for FEA to be done on each element. However, the element numbering was not arranged sequentially by APDL, but as shown in Figure 7 .

\subsection{Stress Contour Diagram and Maximum Stress Distribution}

The stress contour diagram for the equivalent stress or Von Mises stress was plotted to investigate the stress distribution on the pipe. Figure 8 showed a plot of the stress contour diagram for the model. The diagram showed that the maximum and minimum equivalent stress experienced by the pipeline was displayed on the top side and bottom side of the pipe, respectively.

Figure 9 shows a plot of the maximum stress induced on each element. Four sides of a single element were represented on the graph, namely: the top, bottom, left and right sides of the pipe. This was to identify the element with the highest maximum stress and also know the stress distribution along the sides of the pipe.

It can be observed from Figure 8 and Figure 9 that the maximum stress of $2550.08 \mathrm{~kg} / \mathrm{cm}^{2}$ was induced at the top-side on element number 21 . This element was on the curved section close to the entry point where the angle of $10^{\circ}$ was

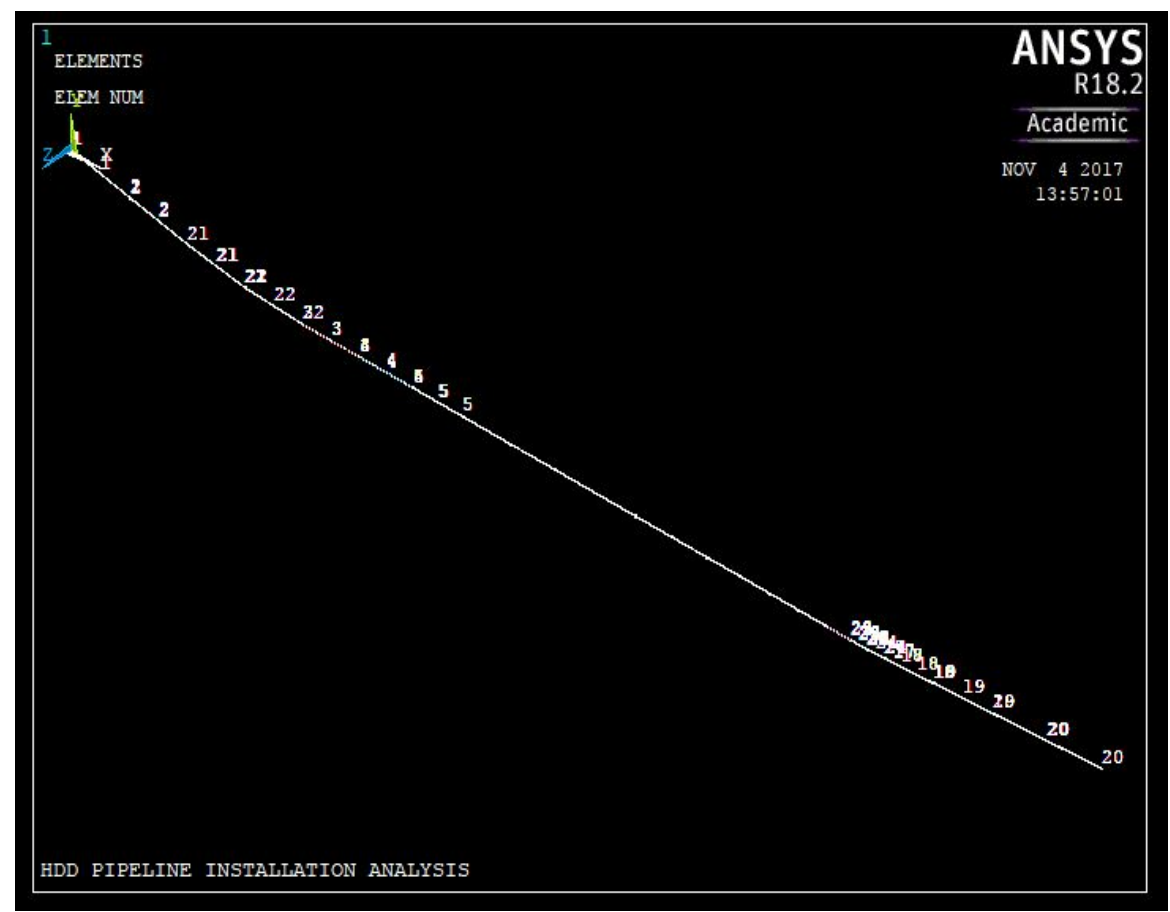

Figure 7. Element numbering on ANYSYS Mechanical APDL. 


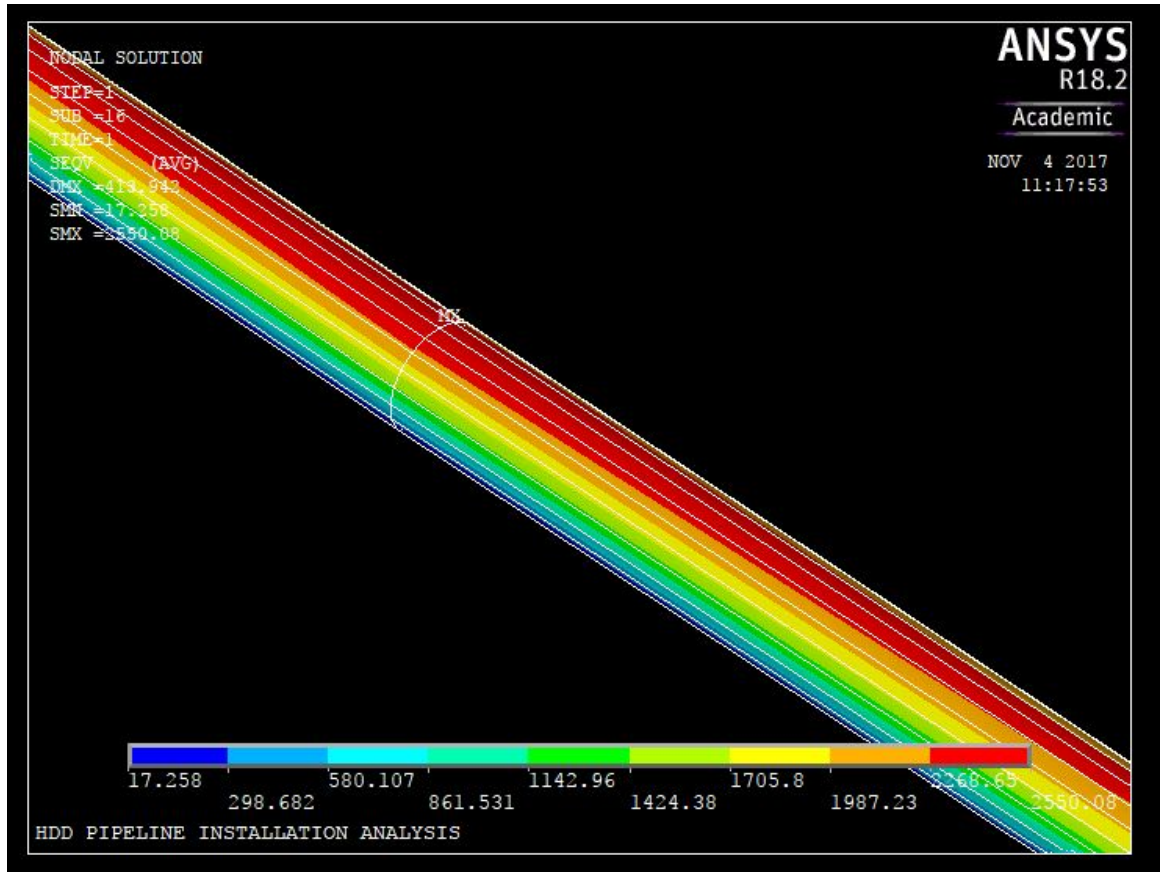

Figure 8. Stress contour diagram.

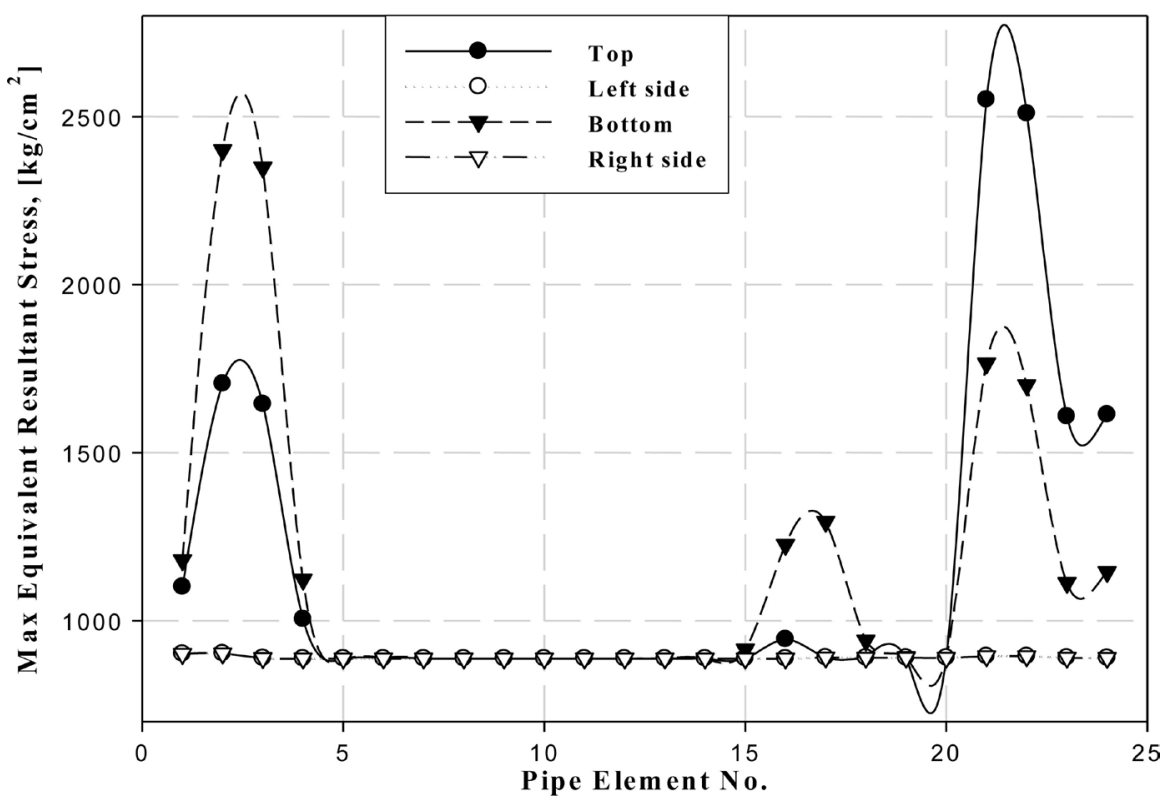

Figure 9. Maximum stress per element around the pipe

used and which was much higher than the $6^{\circ}$ used on the exit point. Although the radius of curvature was the same on both sides (entry and exit side), the maximum stress was experienced by the side with the highest angle. The bottom-side maximum stress $2399.9 \mathrm{~kg} / \mathrm{cm}^{2}$ was obtained at element number 2 . Also, it can be observed from the stress contour diagram, Figure 8 and Figure 9, that the stress on the top and bottom sides of the pipe was considerably higher on the elements in the curved sections of the pipeline.

However, the stress at the left-side and right-side of the pipeline was relatively 
uniform at approximately $888 \mathrm{~kg} / \mathrm{cm}^{2}$ all through the pipeline regardless of the section where it was located. It would have been easily concluded that the stress at the curved sections would be higher than all other sections all-round the pipe, it can be seen that this was not the case.

\subsection{Minimum Stress Distribution}

Figure 10 showed the minimum stress distribution around the pipe for each element which also indicates that the stress distribution along the sides of the pipe all through the pipeline was relatively uniform regardless of the location. However the top and bottom minimum stress varies considerably at the curved sections. The minimum stress at the curved section indicates a lower stress level on the elements with maximum stresses.

The topside minimum stress was $17.237 \mathrm{~kg} / \mathrm{cm}^{2}$ at element number 21 , while the bottom-side minimum stress was $96.784 \mathrm{~kg} / \mathrm{cm}^{2}$ obtained at element number 2. The left-side and right-side minimum stress remained uniform at approximately $888 \mathrm{~kg} / \mathrm{cm}^{2}$ irrespective of the element number.

\subsection{Deflection Plot}

A nodal solution of the pipe deflection was plotted to show the deflection at each section of the pipe. From Figure 11 it can be observed that the maximum and minimum deflection experienced by the pipe was $413.942 \mathrm{~cm}$ and $0.000486 \mathrm{~cm}$, respectively which were displayed on the top left-hand side of the Figure 11 . The exact point of maximum deflection can also be observed in Figure 11. The location point of the maximum and minimum deflection point for the pipeline system was shown in Figure 12.

The plot of the pipeline deflection was shown on Figure 11. This plot in Figure 11

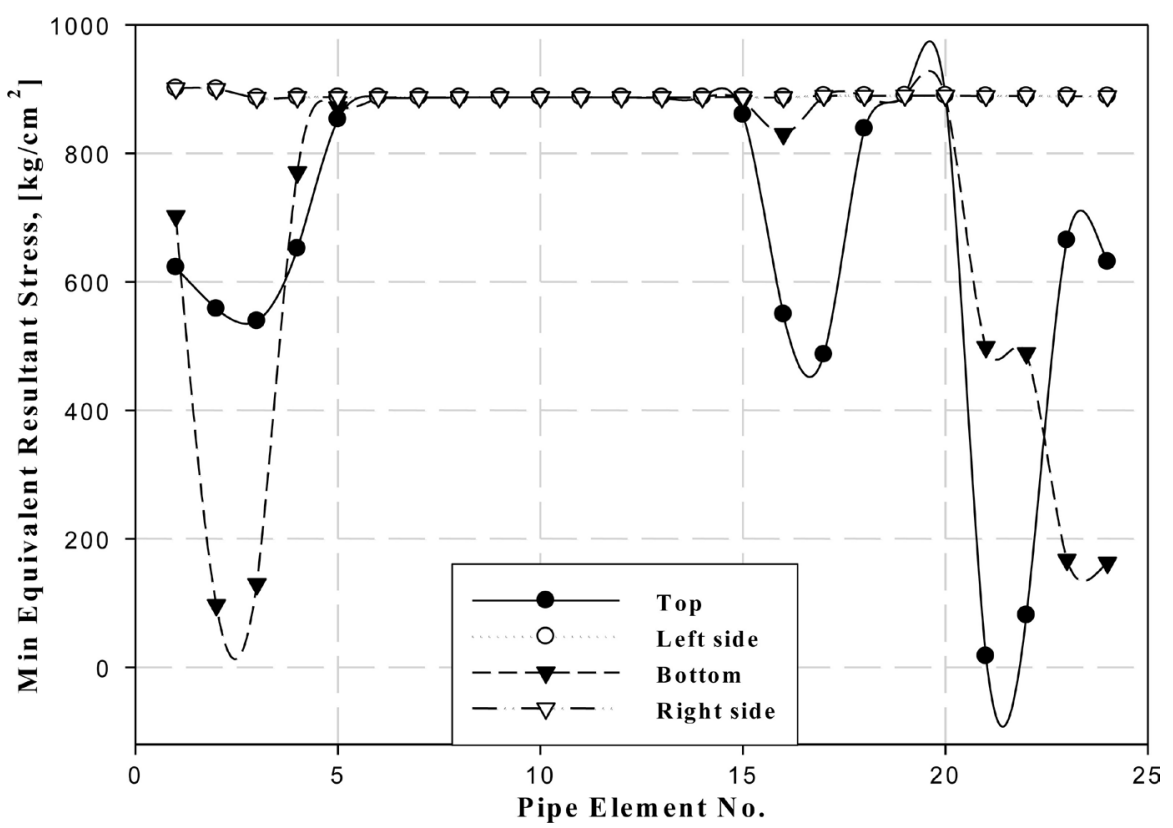

Figure 10. Minimum stress per element around the pipe. 


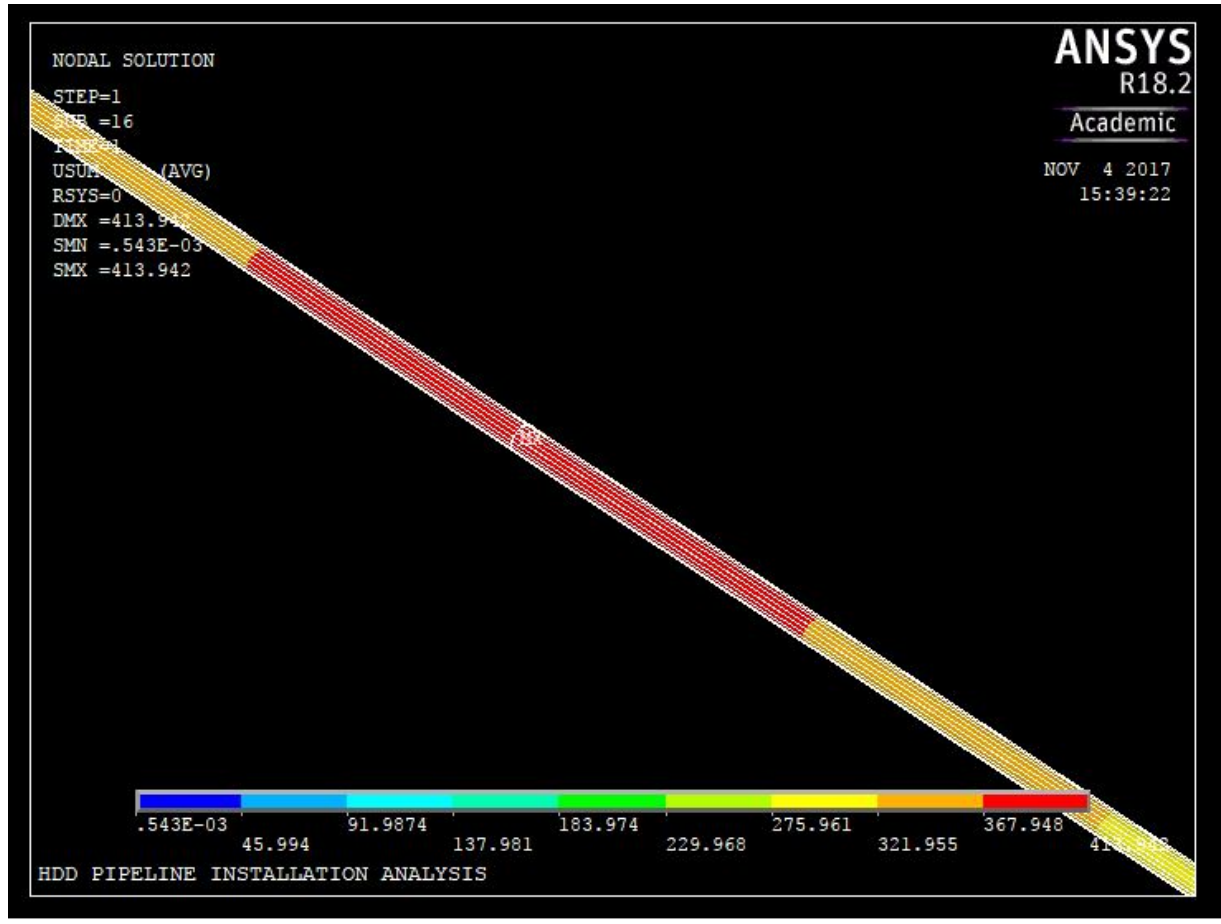

Figure 11. Maximum deflection plot from the model.

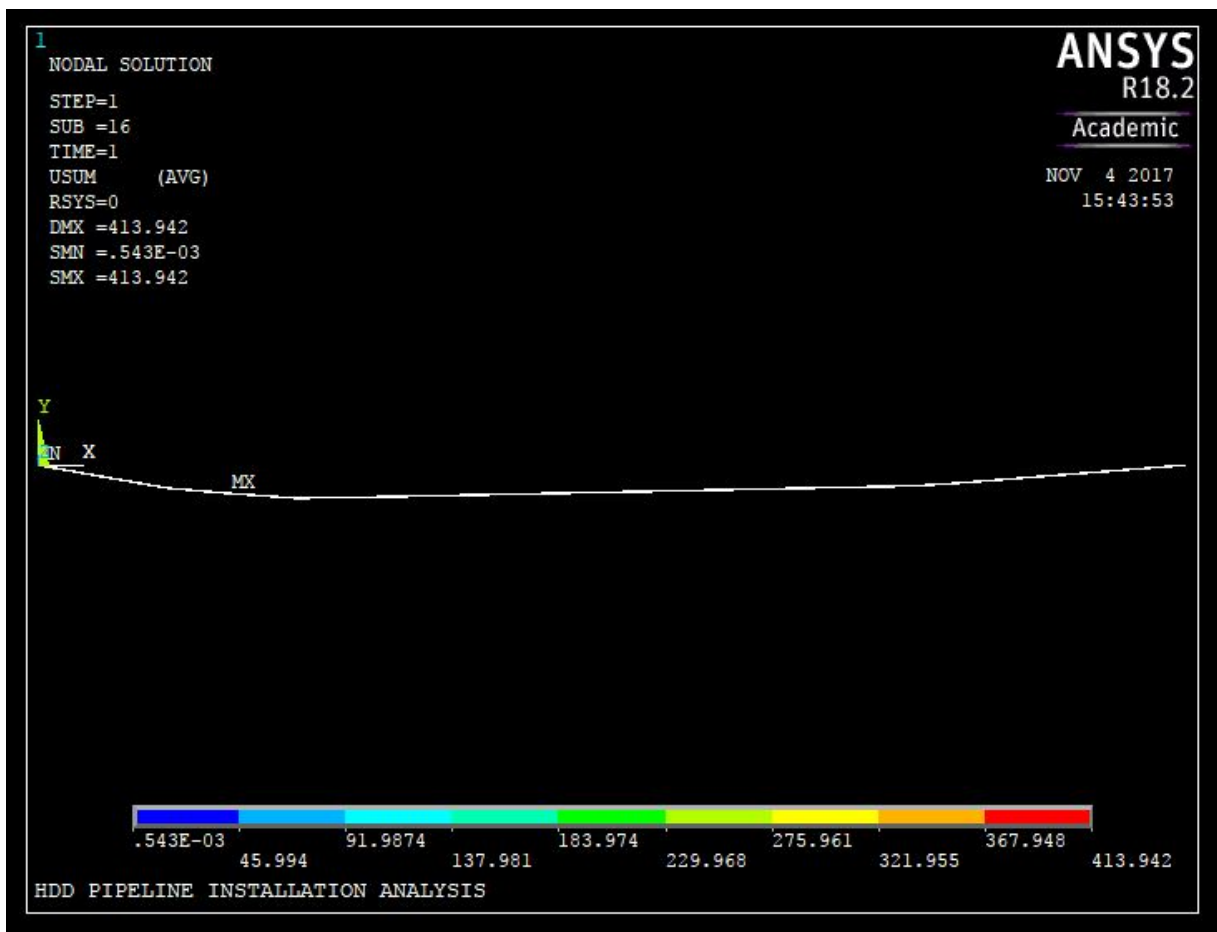

Figure 12. Maximum and minimum deflection point.

indicates that the maximum deflection on the pipeline was experienced at the point of maximum stress level. While, Figure 12 showing the points of the maximum and minimum deflection showed that the minimum deflection was obtained at the entry point of the HDD installation. 


\section{Conclusion}

Hence, ANSYS can be used as veritable tool for the analyses and design of a pipeline system to be installed by horizontal directional drilling (HDD). The results obtained from this study using the ANSYS model were corroborated those of theoretical methods. The point of curvature with the higher angle (that is, if both points of curvature are the same and the entry and exit angles are different) experiences the maximum induced stress. Maximum deflection of the pipeline should be expected at the point with maximum stress as this was due to the high bending moment experienced at this point. On a particular pipeline system, the maximum and minimum stresses were induced at the pipe top-side and bottom-side, respectively; while the stresses at the sides of the pipeline remained relatively uniform with slight variation.

\section{Conflicts of Interest}

The authors declare no conflicts of interest regarding the publication of this paper.

\section{References}

[1] Xiao, J., Chen, J. and Li, Z. (2012) Engineering Analysis of the Buried GRP Pipeline using ANSYS. International Conference on Pipelines and Trenchless Technology, Wuhan, 19-22 October 2012, 825-831. https://doi.org/10.1061/9780784412619.085

[2] Zhang, J., Liang, Z. and Zhao, G. (2016) Mechanical Behaviour Analysis of a Buried Steel Pipeline under Ground Overload. Engineering Failure Analysis, 63, 131-145. ttps://doi.org/10.1016/j.engfailanal.2016.02.008

[3] Nirmala, R. and Rajkumar, R. (2016) Finite Element Analysis of Buried UPVC Pipe. Indian Journal of Science and Technology, 9, 1-5. https://doi.org/10.17485/ijst/2016/v9i5/87225

[4] Huey, D.P., Hair, J.D. and McLeod, K.B. (1996) Installation Loading and Stress Analysis Involved with Pipelines Installed by Horizontal Directional Drilling. Proceedings of the North American Society for Trenchless Technology Conference, New Orleans, LA, 31 March-3 April 1996, 692.

[5] Willoughby, D. (2005) Horizontal Directional Drilling: Utility and Pipeline Applications. McGraw-Hill Professional, New York.

[6] Segerlind, L.J. (1976) Applied Finite Element Analysis. John Wiley \& Sons, Inc., New York.

[7] Rao, S.S. (2011) Finite Element Analysis Using ANSYS. In: Rao, S.S., Ed., The Finite Element Method in Engineering, 5th Edition, Elsevier, Burlington, 663-681. https://doi.org/10.1016/B978-1-85617-661-3.00022-2

[8] Chaudhari, V., Kumar, P.V.D. and Kumar, R.P. (2013) Finite Element Analysis of Buried Continuous Pipeline Subjected to Large Ground Motion. International Journal of Structural Engineering, 4, 314-331. http://www.joes.org.in https://doi.org/10.1504/IJSTRUCTE.2013.056981

[9] Wu, X., Lu, H., Huang, K., Wu, S. and Qiao, W. (2015) Frequency Spectrum Method-Based Stress Analysis for Oil Pipelines in Earthquake Disaster Areas. PLoS ONE, 10, e0115299. https://doi.org/10.1371/journal.pone.0115299 
[10] Huang, K., Wu, J., Hu, M., Xiang, H. and Zhang, Z. (2015) Optimization and Stress Analysis of Underground Oil Pipelines in High and Steep Slope Areas. The Open Civil Engineering Journal, 9, 477-483. https://doi.org/10.2174/1874149501509010477

[11] Gabar, M. and Bilgin, M. (2016) Modeling of Buried Pipe Deformations. IOSR Journal of Mechanical and Civil Engineering, 13, 43-50. 